\title{
The TCO Paradox-A Key Problem in the Diffusion of Energy Efficient Vehicles?
}

\author{
Jens Hagman, Sofia Ritzén, Jenny Janhager Stier \\ School of Industrial Engineering and Management, KTH Royal Institute of Technology, Stockholm, Sweden \\ Email: jenshagm@kth.se, ritzen@kth.se, jennyj@kth.se
}

How to cite this paper: Hagman, J., Ritzén, S. and Stier, J.J. (2017) The TCO Paradox-A Key Problem in the Diffusion of Energy Efficient Vehicles? American Journal of Industrial and Business Management, 7, 1267-1284.

https://doi.org/10.4236/ajibm.2017.712090

Received: October 26, 2017

Accepted: December 8, 2017

Published: December 11, 2017

Copyright $\odot 2017$ by authors and Scientific Research Publishing Inc. This work is licensed under the Creative Commons Attribution International License (CC BY 4.0).

http://creativecommons.org/licenses/by/4.0/

\begin{abstract}
The aim of this paper is to explore how mainstream vehicle buyers perceive and apply Total Cost of Ownership in their vehicle choice process. All else equal, rational consumers ought to evaluate Total Cost of Ownership in order to acquire the real cost of owning a particular vehicle under consideration, unless bounded rationality is affecting their behavior. The results reveal that vehicle buyers generally are capable of understanding the relative size of individual costs that make up vehicle Total Cost of Ownership but fail to evaluate and apply multiple costs in their vehicle purchase process. Regression analysis exposes that income, educational level, stated importance of Total Cost of Ownership and the number of vehicles in the choice set have a positive association with the degree that consumers conduct an evaluation of vehicle Total Cost of Ownership. Failure to consider Total Cost of Ownership can lead to uneconomic vehicle choices, which is here labeled as the TCO paradox. This could have an especially negative effect on the diffusion of battery electric vehicles, which require a more detailed cost analysis in order to extract its low operating cost structure.
\end{abstract}

\section{Keywords}

Total Cost of Ownership, Energy Paradox, Vehicle Choice

\section{Introduction}

A transition towards more sustainable transport solutions is a challenge that is in urgent need to be addressed in order to decrease the negative consequences of the current transport system. Personal vehicles are responsible for $12 \%$ of total $\mathrm{CO}_{2}$ emissions in the European Union [1]. Battery Electric Vehicles (BEVs) that are powered solely by electricity from an on-board battery are now emerging on the mass-market and hold potential to decrease emissions due to higher drive- 
train efficiency and the potential to use renewable electricity for its propulsion. BEVs have thus far only attracted a modest share of vehicle buyers in the EU, both in annual sales and as a share of the total vehicle fleet compared to Internal Combustion Engine Vehicles (ICEVs) [2] [3]. In order to better understand plausible barriers and enablers for a more rapid uptake of BEVs, it is useful to embark in deciphering the quite complex consumer vehicle choice process, in which numerous objectively and subjectively determined factors are individually evaluated and weighted by consumers [4]. Additionally, in marketing and innovation theories on how new products become mass-market products, i.e. in innovation diffusion theories, it is suggested that new products need to be perceived as superior overall to the incumbent solutions in order to diffuse on the market [5] [6]. Superiority related to cost and affordability has been established as one of the pivotal factors in the growth of new consumer durables in general [7] and also confirmed as important in the diffusion of BEVs [8] [9]. Exploring costs/affordability in the vehicle choice process is timely and interesting since BEVs and other energy efficiency products have been found to have different cost characteristics compared to incumbent ICEV (e.g. [10] [11]). The compatibility or incompatibility of the current vehicle cost evaluation behavior with the emerging market for BEVs is as of yet not understood.

BEVs in similarity to other energy efficient products tend to have a significantly higher purchasing price compared to incumbent ICEV [11]. The actual cost of a durable good such as a vehicle is rarely equal to its purchasing price; rather it is the sum of the operating costs and depreciation cost during the ownership period. This summation of costs is often labeled as the Total Cost of Ownership (TCO). TCO plays a vital role in several reports that predict future market penetration of BEVs. One recent example is a report from UBS, where a strong link is suggested between cost parity i.e. TCO of BEVs and their corresponding market uptake [12]. This however assumes that consumers are sufficiently informed of BEVTCO and corresponding TCO of alternative vehicles, for it to translate into adoption. The TCO function for energy efficiency technologies, such as BEVs, does however tend to look different compared to incumbent technologies. Energy efficient technologies usually have a higher purchasing price but lower operating costs compared to less energy efficient solutions, in effect requiring potential buyers to compute and compare operating costs in detail, in order to make a fair cost evaluation of different technologies. This is especially true in the vehicle market where numerous ownership costs such as fuel, maintenance and repair, taxes, depreciation and insurance, need to be included [11]. Vehicle TCO thus contains a larger set of costs items compared to other durable goods, e.g. washing machines, where TCO normally is extracted from two costs items (purchasing price and ownership energy costs). Previous consumer centric studies in the vehicle market have focused exclusively on energy (fuel) cost [13] [14]. The failure of consumers to make a rational choice to adopt and the slow adoption of seemingly high-return investments in energy efficiency have been referred to as the Energy Paradox [15], a phenomenon that has been 
extensively discussed in the literature including possible effect on the vehicle market [16] [17] [18] [19]. The energy paradox has been suggested to be related to market failure factors-information problems and unobserved costs, and non-market failure factors-private information costs, high discount rate and heterogeneity among potential adopters [15]. However, in the previous context of ICEV comparison, it has been suggested that inattention to ownership costs can be rational given small differences in costs and high search costs of getting more informed [19]. That proposition can be challenged given the recent emergence of BEVs as they constitute an offer on the market with a different cost structure than ICEV where TCO is critical for a valid comparison.

The aim of this paper is to explore how mainstream ICEV buyers perceive and apply TCO in their vehicle choice process. Investigating mainstream non-BEV buyers is valuable since it is highly conceivable that purchasing behavior/habits remains relatively sticky over time, notably in such a mature industry as the automobile industry that has seen little disruption in purchasing experience and sales channels. The pretense of this paper is that the ability to extract TCO is based on the individual consumer's motivation and allocation of cognitive resources in information search and computation i.e. their attention to the costs that make up TCO. It can be assumed that the more complete the cost evaluation, the higher propensity to recognize and evaluate technologies with a low operating cost nature that in turn could translate into adoption. Research that investigates the mechanisms that influence TCO evaluation among consumers is however lacking. This is a critical area for policy and industry; understanding the different levels of cost attentiveness across consumers as well as which cost are least understood and applied enables a more effective targeting of activities to promote more energy efficient vehicles. The results of this paper will be translated into suggestions for actions that can speed up the diffusion of energy efficient vehicles in general and for BEVs in particular.

\section{Frame of Reference}

In this section, important theoretical and empirical research that has contributed to the current understanding of vehicle costs and its relation to purchasing behavior is presented. The frame of reference reflects the scope of this paper; vehicle choice in the context of TCO and purchasing price.

\subsection{Vehicle Cost Structure and Total Cost of Ownership}

Vehicles in similarity to other durable goods have a cost structure that not only entails the purchase of the good, but also its use and ownership. TCO have been developed as a useful way to illustrate these cost. Ellram [20] defined TCO as a purchasing tool and philosophy aimed at understanding the true cost of a particular good. In this paper, the authors will use a consumer centric vehicle TCO perspective, i.e. the TCO framework provided by [21], which is relatively easily accessible to consumers. The vehicle costs included in the framework are the 
following (ranked according to average size): depreciation, fuel costs, interest, insurance, maintenance and repair (service) and taxes. Figure 1 illustrates the share of each cost of the total for a typical vehicle on the US market.

Research into vehicle TCO modeling is still in its infancy with large differences in framing and assumptions, although a number of researchers have adopted TCO computation methods in order to calculate and visualize vehicle cost differences [10] [11] [22] [23]. TCO can differ significantly across vehicle types/ models, consumers and markets. Due to factors, such as fuel prices, driving distance, vehicle class, ownership period, consumer preferences, knowledge and other economic costs [22] [23] [24]. A relevant finding related to drivetrains in previous research is the significantly lower operating cost of BEVs compared to ICEV [11] [23]. BEV fuel costs can be up to 90\% lower compared to ICEV [11]. Fewer moving parts in the drivetrain and regenerative braking decrease service needs in the case of BEV. Furthermore, BEVs are frequently subsidized and have lower vehicle taxes in many markets. The higher purchasing price of BEVs on the other hand is converted into higher costs of depreciation, interest cost and to some degree insurance. The countervailing ownership cost structure of BEVs has been applied in TCO simulation research for a number of different assumptions related to use, cost and time. These studies have found that plug-in hybrid vehicles (PHEV) and BEV can be either cheaper or more expensive to own compared to ICEV depending on the assumptions made [10] [22] [23] [25]. Determining the profitability of different vehicles require personalized TCO calculations to be of practical relevance. However, calculating TCO is likely a challenging task for consumers, requiring significant time and cognitive abilities [11].

Serving consumers with TCO comparison material in an experimental setting have been found to increase interest in energy conservation products such as vehicles [26] [27]. The absence of widespread TCO comparison tools on the market, require consumers to manually extract and compute vehicle data into a

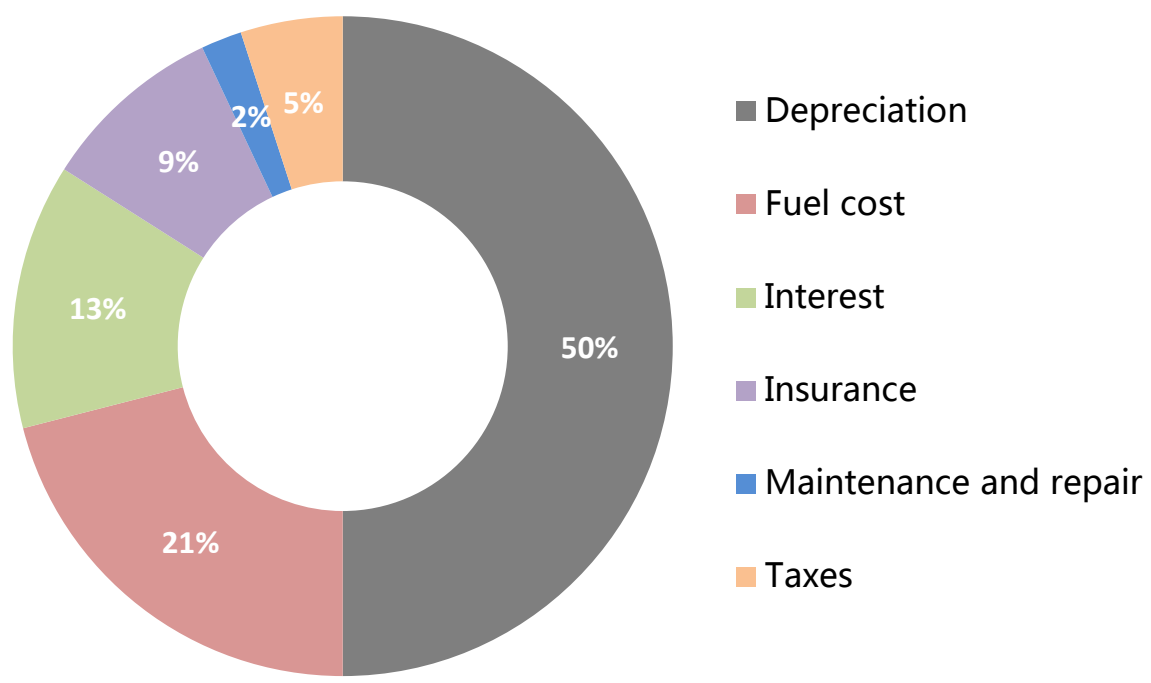

Figure 1. Total cost of ownership for the typical newly bought vehicle in the US over a three-year ownership [21]. 
TCO, in effect placing extensive search costs, motivation and cognitive abilities on the individual consumer. To what degree consumers evaluate the various cost that make up TCO and the relationship with purchasing price is as of yet not clear.

\subsection{Rational Choice Theory, Bounded Rationality and the Energy Paradox}

In traditional economics, it is often assumed that people are fundamentally motivated by money and the possibility to earn a profit. Thus, allowing economist to make formal and predictive models of human behavior [28]. The extension of this line of thinking that all human behavior is essentially rational in its disposition and that human behavior is largely based on pre-behavioral cost/benefit analysis is referred to as rational choice theory [28]. According to rational choice theory must individuals foresee the outcomes of alternative course of actions and compute the alternative that is most applicable for them [28]. Applied to the vehicle market it would entail that the actual differences in TCO between vehicles (e.g. [11]) would necessitate consumers to evaluate TCO before choosing the "right" vehicle. Rational choice theory enables theoretically eloquent behavior models but as a practical tool it has been criticized for its shortcomings, such as for its limited assumptions and predictive powers. These limitations have given rise to complementary models of economic thinking, where the field of behavioral economics plays a prominent role in making economic models more psychologically tenable. A central theme in behavioral economics is the concern with bounded rationality, which refers to rational choice that takes into account cognitive limitations of the decision maker; limitations of both knowledge and computational capacity [29]. Thus, the choices that individuals make are not only derived from goals and properties of the external world, but also internal knowledge, cognitive abilities to determine relevance information and consequences of their action, coping with uncertainty, and to choose among numerous competing wants. Rationality can be bounded if these abilities are severely limited [29].

The energy paradox is an adjacent theory that has gained some prominence in the adoption energy efficiency literature. Energy efficiency is often described as a "win-win", by simultaneously saving money and reducing negative externalities associated with energy use, implying that adoption of energy efficiency can be profitable and ought to be a rational choice from profit maximizing actors. If consumers do not undertake these privately profitable investments in energy efficiency an Energy Paradox could be present on the market [24]. The Energy Paradox has been described as the very gradual diffusion of apparently cost-effective energy-conservation technologies [15]. The potential to profitably decrease energy consumption and emissions through investments in energy conservation technologies have been highlighted in numerous studies [30] [31]. The energy paradox had been explained as being related to market failures; imperfect information and inattention and non-market failure; private information 
costs, high discount rate, and heterogeneity among potential adopters [15] [24]. Imperfect information can either entail that consumers are simply unaware of potential gains in energy investments or aware that difference in cost exist but that the differences are too costly (time, effort, etc.) to observe [24]. Inattention entails that consumers are misoptimizing by failing to fully observe and incorporate important facets of a purchase such as running costs, rather choosing to focus on purchasing price [24]. Illustrated in the finding that consumers choosing among products are less attentive to ancillary costs than to purchasing price [16], such as the low salience of fuel costs when consumers are choosing or owning a vehicle [13] [32]. For example, leading consumers to evaluate BEVs as more expensive compared to ICEV [27].

Sallee [19] suggests that inattentive to energy efficiency in markets, such as the vehicle market could be a rational choice by consumers. Rational inattention is defined as when information is costly to acquire, decisions makers may sometimes choose to act upon incomplete information, rather than incurring the cost to become perfectly informed. Rational inattention is more likely when efforts costs are high, the variance of unknown energy costs are low, and products are very different to each other and hence cannot be classed as close substitutes [19]. The ongoing discussion in the energy paradox literature illustrates the complexity of consumer purchase decision of long-term use goods such as vehicles; generalizability of the whole population is a challenging task. It has been suggested that there is substantial heterogeneity in the implicit weight of energy savings in the purchase decision across the population leading to different levels of investment inefficiencies [24].

\subsection{Research Questions}

The vehicle choice process is influenced by an array of individual considerations and evaluations by the consumer on numerous different choice factors, where economic factors play a prominent role. Rational economic behavior would imply the need for consumers to evaluate TCO in their vehicle choice process; enquiring the real cost of owning and using a vehicle I necessary for economically optimal purchasing choices. This paper explores to what degree mainstream consumers evaluate TCO, what infers them to be more or less attentive to vehicle costs. This paper can yield valuable insights into economic behavior in the vehicle choice process, which, plausibly have implications for the diffusion of energy efficient vehicles such as BEVs. The following research questions are addressed:

1) How do consumers evaluate vehicle total cost of ownership?

2) What influence consumers to evaluate vehicle total cost of ownership?

\section{Method}

\subsection{Sample Description}

An internet-based survey was constructed and used in this study in order to col- 
lect data from mainstream new vehicle buyers in Sweden during the autumn of 2014, aimed to represent the general composition of new vehicle buyers rather than early adopters of energy efficient vehicles such as BEVs. The survey was distributed by Intermetra $A B$, a local survey collection company with many years of experience within the automobile sector. In similarity to [33], do the authors categorize the consumers as "new vehicle buyers", defined as consumers who either bought a new or at the most two-year-old vehicle within the last 12 months or consumers planning to buy a new or at the most two-year-old vehicle within the next 12 months, including private and employee leasing options. In 2015 , a total of 345,108 new vehicles were sold on the Swedish market [34]. An initial pilot survey with 100 respondents enabled the authors to modify the survey for clarity in the final version. For the final survey a total of 12,570 potential respondents in Intermetra's database were contacted through e-mail with a response rate of $39.7 \%$; of those 4990 respondents $19.6 \%$ was identified as "new vehicle buyers", composing the total number of 980 respondents that has been analysed in this study, of which none own an BEV. The characteristics of the respondents are depicted in Table 1.

The authors used stratified random sampling in order to capture a degree of heterogeneity in terms of income, age, geographic location and household composition from the new vehicle buyer population. Low VIF scores indicate that there are small problems with multicollinearity in the sample population.

\subsection{Survey Design}

The survey questions were inspired by previous studies testing for attitudes among vehicle buyers for green vehicles on vehicle choice factors such as [8], [33]. The respondents could skip individual questions although a response item representing "I do not know/not applicable" was used whenever possible. The question items used in this paper consist of a sub-set of the questions applied in the complete survey. These questions have been selected to measure consumers' level of information and attention to vehicle costs in general. Question items in the survey that measures aspects such as lifestyle are beyond the scope of this paper but are likely to be important in the vehicle choice process and will therefore be used in subsequent research by the authors.

\subsection{Data Analysis}

The respondents were segmented based on the number of cost they calculated before they purchased their current vehicle, which was used as a proxy variable for their level of TCO Attentiveness, here depicted as $T A$. Conducting a vehicle cost calculation requires allocation of mental resources into information search and computation methods. All else equal, the more cost included in the calculation, the larger is the allocation of mental resources and the induced importance of operating costs. The authors therefore argue that cost attentiveness can be reasonably measured by the proxy of number of cost included in the ex-ante cost calculation. Acknowledging that information is missing of accuracy and time 
Table 1. Characteristics of the respondents.

\begin{tabular}{|c|c|c|}
\hline Variables & Number of responses & $(\%)$ \\
\hline \multicolumn{3}{|l|}{ Gender } \\
\hline Female respondents & 361 & 37 \\
\hline Male respondents & 619 & 63 \\
\hline \multicolumn{3}{|l|}{ Education } \\
\hline Elementary school education & 70 & 7 \\
\hline High school education & 369 & 38 \\
\hline University degree & 541 & 55 \\
\hline \multicolumn{3}{|l|}{ Household members } \\
\hline Single household & 120 & 12 \\
\hline Couple/Married & 587 & 60 \\
\hline Single parent & 27 & 3 \\
\hline Couple/Married with children & 230 & 23 \\
\hline Other & 16 & 2 \\
\hline \multicolumn{3}{|l|}{ Place of residence } \\
\hline Large city & 274 & 28 \\
\hline Medium-sized city & 184 & 19 \\
\hline Small city & 364 & 37 \\
\hline Rural area & 158 & 16 \\
\hline \multicolumn{3}{|l|}{ Age } \\
\hline $18-24$ & 24 & 2 \\
\hline $25-34$ & 106 & 11 \\
\hline $35-44$ & 189 & 19 \\
\hline $45-54$ & 198 & 20 \\
\hline $55-64$ & 206 & 21 \\
\hline $65-74$ & 221 & 23 \\
\hline Older than 75 & 36 & 4 \\
\hline \multicolumn{3}{|l|}{ Household monthly income* } \\
\hline Less than 15,000 SEK & 12 & 1 \\
\hline $15,001-25,000$ SEK & 73 & 7 \\
\hline $25,001-35,000$ SEK & 149 & 15 \\
\hline $35,001-45,000$ SEK & 141 & 15 \\
\hline 45,001 - 55,000 SEK & 127 & 13 \\
\hline $55,001-65,000$ SEK & 150 & 15 \\
\hline $65,002-85,000$ SEK & 114 & 12 \\
\hline $85,001-10,5000$ SEK & 54 & 6 \\
\hline More than 105,000 SEK & 42 & 4 \\
\hline Do not wish to disclose & 118 & 12 \\
\hline
\end{tabular}

${ }^{\star} 1 \mathrm{SEK} \approx € 0.1$. 
spent into the different costs. The segmentation was conducted through two survey questions that was mapped with the six cost TCO framework used in [11] [21]. Firstly, the respondents were asked to think back to the process before they bought their current vehicle and indicate if they estimated future vehicle cost ex-ante. Second, respondents that had conducted an ex-ante cost calculation was asked to indicate what cost they included in their calculation.

In order to assess the research questions proposed in this paper several descriptive and statistical tests have been applied to the dataset. The statistical analysis was made with the SPSS Statistics software. Research question one is analyzed through a descriptive lens, applied on: number of cost evaluated ex-ante ( $T A$ variable), cost included, reasons for not conducting a cost evaluation, stated importance of purchasing price and TCO, and knowledge of vehicles costs. To assess research question two a multiple predictor OLS regression model was created and applied to the dataset. The $T A$ variable will be used as the dependent variable in the model. A number of independent variables are proposed to explain the variance in the dependent variable. Social demographic variables are commonly used control variables that plausibly could influence consumers cost attentiveness. More educated people have for instance been found to be more prone to calculate ex-ante fuel costs, arguably due to higher cognitive computation abilities [14]. Age and income could similarly proximate abilities and motivations for cost attentiveness. A general interest in vehicles is included in the model since the step from general interest of vehicles to a more specific interest in vehicle cost, all else equal, ought to be smaller than from no interest. In similarity with the model of investment in energy efficiency proposed by [24] will our model include usage of vehicles, measured in kilometers driven annually? Additionally, it could be imagined that the number of vehicles in the purchase consideration set could influence level of cost attentiveness. More comparative information such as vehicle cost differences ought to signify a larger importance when deciding between a numerous set of vehicles compared to one or a selected few vehicles. The importance of TCO in the vehicle purchase decision ought to affect the motivation to be informed about vehicle costs; therefore, influence the probability to conduct a cost evaluation ex-ante. The importance of purchasing price in the vehicle purchase decision was included in the model as a control variable for heuristic information. Table 2 depicts the variables used in the model.

\section{Empirical Results}

In this section, the respondent's evaluation of vehicle cost will be presented, followed by the regression results aimed at answering research question two.

\subsection{Vehicle Cost Calculation Ex-Ante}

$58 \%$ of the respondents did not conduct an ex-ante vehicle cost computation and just $9 \%$ did a cost calculation that included more than four cost items. The 
Table 2. Cost attentiveness influence model.

\begin{tabular}{|c|c|}
\hline Variable & Description \\
\hline \multicolumn{2}{|l|}{ Dependent variable } \\
\hline $\begin{array}{c}\text { Total cost of } \\
\text { ownership attentiveness }\end{array}$ & $\begin{array}{l}\text { Continuous variable measuring the number of } \\
\text { cost included in ex-ante cost evaluation }\end{array}$ \\
\hline \multicolumn{2}{|l|}{ Independent variables } \\
\hline TCO & $\begin{array}{l}\text { Continuous Likert type variable measuring the } \\
\text { importance of TCO in the vehicle choice process }\end{array}$ \\
\hline Purchasing price & $\begin{array}{l}\text { Continuous Likert type variable measuring the } \\
\text { importance of purchasing price the vehicle choice process }\end{array}$ \\
\hline Male & Dummy variable for male individuals \\
\hline High School & Dummy variable for individuals with a high school education \\
\hline University & Dummy variable for individuals with a university degree \\
\hline Age $18-34$ & Dummy variable for individuals that are 18 to 34 years old \\
\hline Age $65+$ & Dummy variable for individuals that are older than 65 years old \\
\hline Middle income & $\begin{array}{l}\text { Dummy variable for households that have gross } \\
\text { annual incomes between } € 35,000 \text { - } € 65,000\end{array}$ \\
\hline High income & $\begin{array}{l}\text { Dummy variable for households that have gross } \\
\text { annual incomes above } € 65,000\end{array}$ \\
\hline Vehicle interest & $\begin{array}{l}\text { Continuous Likert type variable measuring } \\
\text { the general vehicle interest }\end{array}$ \\
\hline Annual driving distance & $\begin{array}{l}\text { Continuous variable measuring the annual } \\
\text { driving distance in km range }\end{array}$ \\
\hline No of vehicle models & $\begin{array}{l}\text { Continuous variable measuring the number of } \\
\text { vehicle in the purchase consideration set }\end{array}$ \\
\hline
\end{tabular}

distribution of the number of cost comprises the seven-graded cost attentive variable, which will be used in subsequent analysis. A graphical illustrated of the responses can be seen in Figure 2.

$42 \%$ conducted some kind of cost computation before their vehicle purchase. Insurance proved to be the most prevalent cost to include in the cost computation (31\%), followed by fuel costs (29\%). A minuscular share of the respondents included depreciation and interest cost in their cost computation (8\%). Table 3 illustrates to what degree the different cost that make up TCO was included in the cost computation.

Among the $58 \%$ of respondents that did not conduct at cost computation, close to half (44.7\%) indicated that they did not believe that a cost computation was important or needed in their vehicle purchase decision. $16.8 \%$ indicated that they had an approximate understanding of the costs, 9.4\% did not know why they did not conduct and cost computation and $7.9 \%$ stated negligence or lack of time.

\subsection{Stated Importance of TCO and Purchasing Price}

The survey also probed for the importance of different factors in the vehicle purchase process, where TCO and purchasing price is of particular interest for 


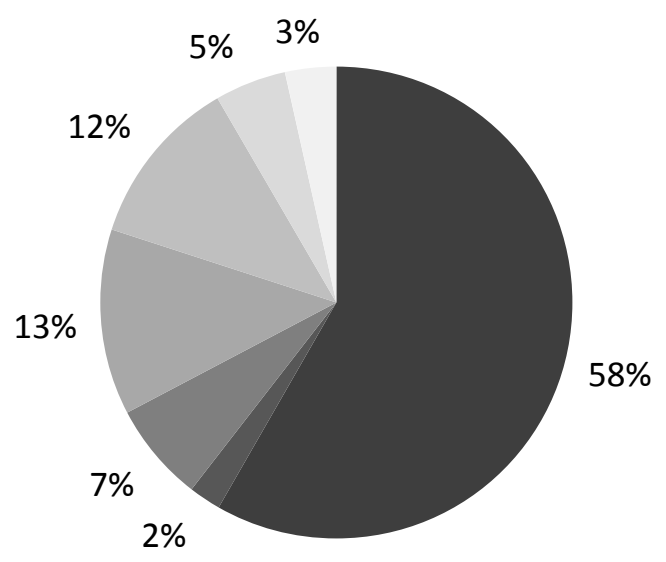

No ex ante cost estimation

- One cost estimation

Two cost estimation

Three cost estimation

$\square$ Four cost estimation

Five cost estimation

Six cost estimation

Figure 2. Ex-ante vehicle cost computation. $\mathrm{N}=980$, Mean: 2.46, Std. Dev: 1.91 .

Table 3. Cost included in the ex-ante cost computation.

\begin{tabular}{ccc}
\hline Variable & $\mathrm{N}$ & $\%$ \\
\hline Insurance & 305 & 31 \\
Fuel cost & 281 & 29 \\
Service and maintenance & 254 & 26 \\
Taxes & 214 & 22 \\
Depreciation & 75 & 8 \\
Interest cost & 74 & 8
\end{tabular}

Answers not related to potential variances between vehicles have been excluded (e.g. parking and smog tests).

the scope of this paper. Respondents rated purchasing price as a slightly more important factor in their vehicle choice compared to TCO, as indicated by the frequencies and means in Table 4.

\subsection{Knowledge of Vehicle Costs}

The respondents were asked to rank the relative size of the individual costs that make up vehicle TCO. They ranked Depreciation and Fuel costs as number one and two respectively, followed by Service and maintenance (third largest), Insurance (fourth largest), Interest cost (fifth largest) and taxes (sixth largest). Table 5 depicts the descriptive statistics of the respondents ranking of the size of each vehicle cost on average over a three-year ownership period.

Another set of survey questions probed for knowledge level of ownership costs for the respondent's current vehicle. The highest stated knowledge level can be seen for Insurance, Taxes and Interest costs. For Fuel costs did $68.9 \%$ indicate that they have an approximate understanding of the Fuel cost of their current vehicle and $9.5 \%$ an exact understanding of Fuel costs. The least understood cost is Depreciation with 55\% of the respondents not knowing its costs. For Service and Maintenance the majority of the respondents had an approximate understanding of its costs (57.7\%). Table 6 illustrates the findings. 
Table 4. Importance of TCO and Purchasing Price in vehicle choice.

\begin{tabular}{ccccccccccc}
\hline Variable & 1 & 2 & 3 & 4 & 5 & 6 & 7 & Do not know & Mean Std. dev \\
\hline TCO & 34 & 32 & 88 & 166 & 232 & 232 & 189 & 7 & 5.00 & 1.60 \\
& $4 \%$ & $3 \%$ & $9 \%$ & $17 \%$ & $24 \%$ & $24 \%$ & $19 \%$ & $1 \%$ & & \\
Purchasing & 13 & 18 & 54 & 141 & 236 & 266 & 248 & 4 & 5.40 & 1.40 \\
Price & $1 \%$ & $2 \%$ & $6 \%$ & $14 \%$ & $24 \%$ & $27 \%$ & $25 \%$ & $0 \%$ & & \\
\hline
\end{tabular}

$\mathrm{N}=980$, Likert type scale where: $1=$ not at all important and $7=$ very important.

Table 5. Ranking of vehicle costs.

\begin{tabular}{cccc}
\hline Cost & \multicolumn{3}{c}{ Survey } \\
\cline { 2 - 4 } & Mean Rank & Std. Dev & $\mathrm{N}$ \\
\hline Depreciation & 1.53 & 1.21 & 980 \\
Fuel cost & 2.94 & 1.46 & 980 \\
Service and maintenance & 3.74 & 1.42 & 980 \\
Insurance & 3.85 & 1.17 & 980 \\
Interest cost & 4.11 & 1.62 & 980 \\
Taxes & 4.82 & 1.99 & 980
\end{tabular}

Table 6. Knowledge of current vehicle costs.

\begin{tabular}{|c|c|c|c|c|}
\hline \multirow{2}{*}{ Cost } & \multicolumn{4}{|c|}{ Stated knowledge } \\
\hline & Knows exactly & Knows approx & Do not know & Knowledge Score* \\
\hline Depreciation & $4.9 \%$ & $40.1 \%$ & $55 \%$ & 0.50 \\
\hline Fuel cost & $9.5 \%$ & $68.9 \%$ & $21.6 \%$ & 0.88 \\
\hline Interest cost & $44.4 \%$ & $19.6 \%$ & $36 \%$ & 1.08 \\
\hline Insurance & $51.6 \%$ & $38 \%$ & $10.4 \%$ & 1.41 \\
\hline Service and maintenance & $20.7 \%$ & $57.7 \%$ & $21.6 \%$ & 0.99 \\
\hline Taxes & $49.1 \%$ & $35.3 \%$ & $15.6 \%$ & 1.33 \\
\hline
\end{tabular}

${ }^{\star}$ Mean score for all respondents where $0=$ Do not know, $1=$ Knows approximately, $2=$ Knows exactly.

\subsection{Factors That Influence Attentiveness to TCO}

In order to test the cost attentiveness influence model described in Section 3.4 an OLS regression was conducted. The results are depicted in Table 7.

The OLS regression indicates that stated importance of TCO, number of vehicle models investigated during purchase decision, level of income and the level of education have a statistically significant impact on $T A$, i.e. the number of cost included in the cost computation. Holding all other variables constant; a one-unit increase in stated importance of TCO (on a seven-graded scale) corresponds to a 0.337 unit increase in number of costs included in the cost calculation, for No of vehicle models the coefficient reveals an increase of 0.226 unit per each incremental vehicle included in the consideration set. Individuals with a high school degree include on average 0.481 more $\mathrm{nr}$ of cost compared to the 
Table 7. OLS regression results.

\begin{tabular}{cccc}
\hline Variables & \multicolumn{2}{c}{ Unstandardized Coefficients } & \multirow{2}{*}{ Sig. } \\
\cline { 2 - 3 } Constant & B & Std. Error & \\
TCO & -0.844 & 0.450 & 0.061 \\
Purchasing price & 0.337 & 0.041 & $0.000^{* * *}$ \\
Male & 0.041 & 0.049 & 0.401 \\
High school & -0.067 & 0.141 & 0.636 \\
University & 0.481 & 0.261 & $0.066^{*}$ \\
Age 18 - 34 & 0.467 & 0.256 & $0.069^{*}$ \\
Age 65+ & 0.270 & 0.190 & 0.155 \\
Income 35 K - 65 K & -0.149 & 0.153 & 0.330 \\
Income 65+ K & 0.250 & 0.151 & $0.098^{*}$ \\
Vehicle interest & 0.393 & 0.182 & $0.031^{* *}$ \\
Annual driving distance & 0.038 & 0.037 & 0.317 \\
No of vehicle models & 0.040 & 0.037 & 0.284 \\
\hline
\end{tabular}

$\mathrm{R}^{2}=0.131$; Adjusted $\mathrm{R}^{2}=0.118, \mathrm{~F}=10.408$; Sig. $=0.000$, Durbin-Watson $=1.919, \mathrm{~N}=844,{ }^{* *}$ Significant at the 1 percent level, ${ }^{*}$ Significant at the 5 percent level, ${ }^{\star}$ Significant at the 10 percent level.

base group with only middle school degrees, the corresponding increase for university degree holders are 0.467 . Consumers with middle income $(35 \mathrm{~K}-65$ $\mathrm{K}$ ) include on average 0.250 unit more $\mathrm{nr}$ of costs compared to the low income base group, whereas the high-income group $(65+\mathrm{K})$ on average include 0.393 unit more number of cost.

\section{Analysis and Discussion}

This paper is built on the premise that in order to make rational economic choices consumers must be informed of all (or at least most) of the costs associated with use and ownership of the purchased good. This requires consumers to conduct an ex-ante TCO evaluation, which takes time and cognitive abilities, particularly in the case of vehicles that have multiple cost items associated with its ownership [11]. The failure to do so can lead to inefficient investment decisions both financially and environmentally, which the authors claim is the TCO paradox, akin to the energy paradox but with the inclusions all ownership costs. The large dataset, focus on mainstream consumer and pronounced results in this paper allows the authors to make generalized claims over time and for other contexts (markets and industries), for example illuminating to how current purchase behavior for ICEV can affect the future market for BEVs.

\subsection{Evaluating TCO}

The results of this paper indicate that evaluating vehicle costs are not a prevalent behavior among consumers, the magnitude of which is apparent in that $58 \%$ of 
consumers do not evaluate vehicle costs in any structured way and only $4 \%$ conducts a complete TCO evaluation. The commonly stated reason of "not being important" or "have an approximate understanding" for not evaluating any of the vehicle costs indicate that a large share of consumers have either failed to recognize that large differences in TCO can exist between different vehicles i.e. are imperfectly informed or simply inattentive to ownership costs and focus their attention elsewhere [24] (Alcott and Greenstone, 2012). Complementary evidence to this include the finding that purchasing price is ranked as slightly more important than TCO on average, signaling inattention for the ownership costs that make up TCO in favor of purchasing price. The results also revealed several paradoxical relationships between knowledge and behavior among consumers. Consumers are in general well informed of the relative size of each vehicle TCO costs items, where depreciation and fuel costs are ranked as the largest ownership costs for ICEV, which is coherent with previous studies (e.g. [11] [21]). This does not however translate to actual behavior in ex-ante cost evaluation, where only $8 \%$ included depreciation and $29 \%$ included fuel costs. Consumers are also clearly struggling to estimate the same costs for their current vehicle; where Depreciation and Fuel cost have the lowest knowledge scores. Difficulties in estimating Depreciation and Fuel costs are to some extent understandable. The actual cost of Depreciation can only be fully known once the vehicle has been sold on the second-hand market. The resell value is influenced by market conditions and level of use during the ownership, although dealerships can assist in estimating an approximate resell value when setting up financing or leasing of the vehicle. Fuel costs by its very nature are prone to vary over time due to variance in fuel prices and changing drive patterns during the ownership. Albeit, it is possible to make estimations based on current conditions and the cost saving potential of doing so is understood by the consumers, the lack of which must therefore originate from other factors such as time and effort needed to become more informed about the vehicle(s) under consideration. For Interest cost, consumers both fail to understand its importance as well as including it in an ex-ante cost evaluation. One possible explanation is a failure to recognize the opportunity cost of capital (discount rate) among the consumers that bought their vehicle in cash. Insurance is the cost that is the best understood by consumers as well as being the cost that are most prevalent in ex-ante cost evaluation. Insurance cost estimates benefit from being both easily compared through online comparison sites as well as being relatively stable over time and hence easier to extrapolate over the length of the ownership. Service and maintenance costs prone to vary depending on size and magnitude of the individual service in the service plan. Recent developments in the market with flat monthly service fees could make service more comprehensible for consumers, possibly explaining the approximate understanding of its value by consumers.

\subsection{Influencing Factors for Evaluation of TCO}

In regards to the factors that were proposed to influence consumers to be more 
informed several novel and interesting results were found. The results indicate a strong positive relationship between consumers stated importance of TCO for their choice of vehicle and number of costs included in their ex-ante cost evaluation. A link that is logically sound, although somewhat contrasting to the discrepancy discussed earlier for the individual cost items of depreciation and fuel costs in terms of relative size and knowledge. Previous research has found that educated people are more prone to calculate ex-ante fuel costs [14], a finding that is confirmed for TCO in this paper. A similar pattern can be seen for income where higher income equates to more costs included in the cost evaluation. It is possible that more educated and high-income individuals possess the cognitive abilities and the understanding required to become more informed about vehicle TCO and consequently could be expected to make more economically rational vehicle purchases. Although the need of using TCO ought to be larger in lower income brackets since vehicle costs are likely to make up a larger share of their household's disposable income. The equality effect of uneconomic vehicle and other durable good purchasing is therefore an interesting area for future research. A positive relationship between number of vehicles being considered and the number of cost included in the TCO computation was also found. Thus, indicating that consumers that compare more vehicle options are acting more rationally in term of TCO in their vehicle choice process. It is interesting that increasing the consumer choice function with one parameter; choosing among multiple options also coincide with including another parameter; evaluating more vehicle costs. In effect, incurring multiple additional search cost compared to consumers that choose between fewer vehicles. Possibly indicating that rationality in cost evaluation is just one expression of a general desire to optimize purchase choice. It is obvious that large differences exist in terms of attention to TCO across the population although the overall level could be considered low. Differences in cost rationality is largely driven by education, income and other proxies for making sound consumer choices such as comparing multiple vehicle options and being aware of the importance of TCO.

\subsection{Implications for the Diffusion of Energy Efficient Vehicles}

The implications of these results for the diffusion of energy efficient vehicles in general and BEVs in particular are multifaceted and potentially quite significant. That BEVs have cost advantages in several of the costs that make up TCO are well established in the literature, which in certain current use and market cases can lead to lower TCO compared to incumbent ICEVs [11]. Reports that predict future market penetration of BEVs have suggested that BEVs are due to reach TCO parity in most use and markets contexts in the near future, consequently leading to adoption by a large proportion of consumers, provided that other barriers such as range and charging is sufficiently mitigated [12]. The results of this paper suggest that one vital element is lacking for this to occur, the knowledge and application of TCO in the vehicle purchasing process. It is not likely that consumers will radically change their ex-ante evaluation behavior due to the 
introduction of BEVs on the market, i.e. the vehicle choice process is likely sticky over time. The failure of consumers to acknowledge the importance of TCO in relation to purchasing price and the obvious lack of applying TCO in their vehicle choice process is therefore problematic for the diffusion process of BEVs. BEVs have a higher purchasing price and could thus risk being evaluated in an approximate fashion as significantly more expansive than its actual TCO and incumbent ICEVs with lower purchasing price. Consumers that currently evaluate TCO are therefore likely a low hanging fruit for grasping the different cost structure of BEVs.

\section{Conclusions}

The aim of this paper is to explore how mainstream ICEV buyers perceive and apply TCO in their vehicle choice process. Overall it can it be concluded that consumers are failing to acknowledge the importance of TCO in relation to purchasing price as well as to take action to evaluate the cost that makes up TCO in their vehicle choice process, plausibly leading to uneconomic vehicle choices or a TCO paradox, which is an extension to the energy paradox but with all ownership costs accounted for. The risk of this is especially apparent in the case of BEVs that have a radically different cost composition with several ownership cost advantages (fuel, service and taxes) compared to ICEVs. Some potential avenues for enabling diffusion of BEVs have been identified from a pure cost and affordability perspective. The TCO paradox is likely an important and promising area for future research and practice but it needs to be stressed that the vehicle purchasing process is a complex process with a large number of objectively and subjectively determined factors that ultimately influence vehicle choice. Disentangling the TCO paradox is thus not a silver bullet of BEV diffusion but rather a barrier among others (e.g. charging and range) that if mitigated would make BEVs and other energy efficient products more appealing to consumers. The following actions are recommended by the authors to mitigate the effect of the TCO paradox.

First, educating mainstream consumers of the importance of TCO in relation to purchasing price for vehicles and other durable goods. One important issue is to highlight the effect that low operating costs could have on TCO. This ought to be carried out in order to increase consumer's motivation to acquire more extensive TCO information. Second, decreasing the search cost of procuring individual (user and product specific) TCO. It is clear from the results in this paper that knowing the importance of TCO is not always sufficient for taking action to compute TCO. Previous experiments with TCO visualizations presented to consumers suggest that such tools hold great potential and ought to be launched on the market. Third, developing new business models that encapsulate TCO can empower consumers to consider ownership costs. Private leasing is one step in that direction, although lacking the inclusion of fuel costs in the monthly payment. An "all-inclusive" business model on the other hand ought to improve 
the relative attraction of BEVs. Finally, to have a substantial impact on the diffusion of BEVs, one could consider to initially aim these activities towards consumers that have already taken rudimentary steps to include TCO in the purchasing process i.e. consumers with higher incomes, higher education and that have taken other rational measures to compare alternatives during their vehicle choice process.

\section{Acknowledgements}

This study was funded by the Swedish Energy Agency.

\section{References}

[1] European Commission (2017) http://ec.europa.eu/clima/policies/transport/vehicles/cars/index_en.htm

[2] European Automobile Manufacturers Association (ACEA) (2016) http://www.acea.be/statistics/tag/category/key-figures

[3] European Commission (2017) https://setis.ec.europa.eu/sites/default/files/reports/Electric_vehicles_in_the_EU.pdf

[4] Lane, B. and Potter, S. (2007) The Adoption of Cleaner Vehicles in the UK: Exploring the Consumer Attitude-Action Gap. Journal of Cleaner Production, 15, 1085-1092. https://doi.org/10.1016/j.jclepro.2006.05.026

[5] Rosenberg, N. (1972) Factors Affecting the Diffusion of Technology. Explorations in Economic History, 10, 3-33. https://doi.org/10.1016/0014-4983(72)90001-0

[6] Rogers, E.M. (2010) Diffusion of Innovations. Simon and Schuster.

[7] Golder, P.N. and Tellis, G.J. (1998) Beyond Diffusion: An Affordability Model of the Growth of New Consumer Durables. Journal of Forecasting, 17, 259-280. https://doi.org/10.1002/(SICI)1099-131X(199806/07)17:3/4\%3C259::AID-FOR696\% 3E3.0.CO;2-T

[8] Egbue, O. and Long, S. (2012) Barriers to Widespread Adoption of Electric Vehicles: An Analysis of Consumer Attitudes and Perceptions. Energy Policy, 48, 717-729. https://doi.org/10.1016/j.enpol.2012.06.009

[9] Carley, S., et al. (2013) Intent to Purchase a Plug-In Electric Vehicle: A Survey of Early Impressions in Large US Cites. Transportation Research Part D: Transport and Environment, 18, 39-45. https://doi.org/10.1016/j.trd.2012.09.007

[10] Al-Alawi, B.M. and Bradley, T.H. (2013) Total Cost of Ownership, Payback, and Consumer Preference Modeling of Plug-In Hybrid Electric Vehicles. Applied Energy, 103, 488-506. https://doi.org/10.1016/j.apenergy.2012.10.009

[11] Hagman, J., et al. (2016) Total Cost of Ownership and Its Potential Implications for Battery Electric Vehicle Diffusion. Research in Transportation Business \& Management, 18, 11-17. https://doi.org/10.1016/j.rtbm.2016.01.003

[12] Hummel, et al. (2017) UBS Evidence Lab Electric Car Teardown-Disruption Ahead? Report, UBS.

[13] Turrentine, T.S. and Kurani, K.S. (2007) Car Buyers and Fuel Economy? Energy Policy, 35, 1213-1223. https://doi.org/10.1016/j.enpol.2006.03.005

[14] Allcott, H. (2011) Consumers' Perceptions and Misperceptions of Energy Costs. The American Economic Review, 101, 98-104. https://doi.org/10.1257/aer.101.3.98

[15] Jaffe, A.B. and Stavins, R.N. (1994) The Energy Paradox and the Diffusion of 
Conservation Technology. Resource and Energy Economics, 16, 91-122. https://doi.org/10.1016/0928-7655(94)90001-9

[16] Allcott, H. and Wozny, N. (2014) Gasoline Prices, Fuel Economy, and the Energy Paradox. Review of Economics and Statistics, 96, 779-795.

https://doi.org/10.1162/REST_a_00419

[17] Greene, D.L. (2011) Uncertainty, Loss Aversion, and Markets for Energy Efficiency. Energy Economics, 33, 608-616. https://doi.org/10.1016/j.eneco.2010.08.009

[18] Bento, A.M., Li, S.J. and Roth, K. (2012) Is There an Energy Paradox in Fuel Economy? A Note on the Role of Consumer Heterogeneity and Sorting Bias. Economics Letters, 115, 44-48. https://doi.org/10.1016/j.econlet.2011.09.034

[19] Sallee, J.M. (2013) Rational Inattention and Energy Efficiency. No. w19545. National Bureau of Economic Research. https://doi.org/10.3386/w19545

[20] Ellram, L.M. (1995) Total Cost of Ownership: An Analysis Approach for Purchasing. International Journal of Physical Distribution \& Logistics Management, 25, 4-23. https://doi.org/10.1108/09600039510099928

[21] Consumer Report. http://www.consumerreports.org/cro/2012/12/what-that-car-really-costs-to-own/

[22] Wu, G., Alessandro, I. and Catharina, B. (2015) Total Cost of Ownership of Electric Vehicles Compared to Conventional Vehicles: A Probabilistic Analysis and Projection across Market Segments. Energy Policy, 80, 196-214. https://doi.org/10.1016/j.enpol.2015.02.004

[23] Davis, M., Alexander, M. and Duvall, M. (2013) Total Cost of Ownership Model for Current Plug-in Electric Vehicles. Electric Power Research Institute, Palo Alto.

[24] Allcott, H. and Greenstone, M. (2012) Is There an Energy Efficiency Gap? National Bureau of Economic Research, No. w17766. https://doi.org/10.3386/w17766

[25] Propfe, B., et al. (2012) Cost Analysis of Plug-in Hybrid Electric Vehicles Including Maintenance \& Repair Costs and Resale Values.

[26] Contestabile, M., et al. (2011) Battery Electric Vehicles, Hydrogen Fuel Cells and Biofuels. Which Will Be the Winner? Energy \& Environmental Science, 4, 3754-3772. https://doi.org/10.1039/c1ee01804c

[27] Kaenzig, J. and Rolf, W. (2010) The Effect of Life Cycle Cost Information on Consumer Investment Decisions Regarding Eco-Innovation. Journal of Industrial Ecology, 14, 121-136. https://doi.org/10.1111/j.1530-9290.2009.00195.x

[28] Scott, J. (2000) Rational Choice Theory. Understanding Contemporary Society: Theories of the Present 129.

[29] Simon, H.A. (2008) Rationality, Bounded. In: Durlauf, S.N. and Blume, L.E., Eds., The New Palgrave Dictionary of Economics, 2nd Edition, Palgrave Macmillan.

[30] Creyts, J., Derkach, A., Nyquist, S., Ostrowski, K. and Stephenson, J. (2007) Reducing U.S. Greenhouse Gas Emissions: How Much at What Cost? McKinsey \& Company.

[31] McKinsey \& Company (2009) Pathways to a Low-Carbon Economy: Version 2 of the Global Greenhouse Gas Abatement Curve.

[32] Greene, D.L., et al. (2005) Feebates, Rebates and Gas-Guzzler Taxes: A Study of Incentives for Increased Fuel Economy. Energy Policy, 33, 757-775. https://doi.org/10.1016/j.enpol.2003.10.003

[33] Lane, B. and Banks, N. (2010) Low CVP Car Buyer Survey: Improved Environmental Information for Consumers. Low Carbon Partnership, London.

[34] BIL Sweden. http://www.bilsweden.se/statistik 